\title{
ADITIF SERAT KAWAT BAJA UNTUK MENAIKKAN KEKANGAN KOLOM BETON PERSEGI
}

\author{
Widayat Amariansah $^{1 \mathrm{a})}$, Antonius ${ }^{2 \mathrm{~b})}$, Soehartono ${ }^{3 \mathrm{c})}$ \\ ${ }_{1,3}^{3}$ Program Studi Teknik Sipil Universitas Pandanaran \\ Jalan Banjarsari Barat no.1, Pedalangan, Banyumanik, Semarang \\ ${ }^{2}$ Program Pasca Sarjana Teknik Sipil Unissula \\ Jalan Raya Kaligawe km.4, Semarang \\ Emaila: widayat62@gmail.com \\ Email ${ }^{b}$ antoni67a@gmail.com \\ Email ${ }^{\mathrm{c}}$ soehartono.sipil@ymail.com
}

\begin{abstract}
ABSTRAK
Gempa tektonik besar berkekuatan 7 skala Richter di Lombok pada 5 dan 19 Agustus 2018 serta gempa dan tsunami Palu-Donggala berkekuatan 7,40 skala Richter pada 28 September 2018, menyebabkan kolom bangunan berpeluang mengalami deformasi yang mengakibatkan selimut beton terkelupas sehingga tinggal inti beton yang harus mempertahankan kekuatan dan daktilitasnya. Hasil penelitian Antonius dkk (2012) menyatakan bahwa penggunaan beton berserat kawat baja pada suhu tinggi dapat meningkatkan sifat daktilitas beton sehingga cocok digunakan pada daerah rawan gempa.

Penelitian ini merupakan lanjutan dari riset Antonius dkk tersebut yang dilakukan terhadap benda uji beton persegi bermutu normal dan mutu tinggi baik yang mengandung serat baja ataupun tidak, pada suhu normal. Hasil pengujian divalidasi terhadap nilai peningkatan tegangan kekang betonnya saat beban puncak $(\mathrm{K})$ terhadap model-model yang telah dikembangkan para peneliti sebelumnya. Hasil penelitian menunjukkan bahwa peningkatan kekuatan dan daktilitas beton berserat baja terkekang dipengaruhi oleh : (1) kuat tekan beton $\left(f_{c}{ }^{\prime}\right),(2)$ ada tidaknya serat baja pada beton dan (3) jarak tulangan lateral (s).
\end{abstract}

Kata kunci : Serat baja, kuat tekan, kolom persegi

\begin{abstract}
Tectonics earthquake with amplitudo $7^{\text {th }}$ Richter scale at Lombok in August, $5^{\text {th }}$ and $19^{\text {th }} 2018$ and earthquake-tsunami at Palu-Donggala with amplitudo $7,40^{\text {th }}$ Richter scale in August, $28^{\text {th }} 2018$, due the column has been deformates which causes the concrete blanket has been exfoliated and so that the concrete core remains its strength and ductility. For this reason, concrete columns must be reinforced with enough lateral reinforcement io receives the peak load in maximum moments. Antonius et al's research (2012) said that the addition of steel wire fibers in concrete with high temperature can increase ductility so is suitable for building in earthquake area.

This study is a continuation Antonius research's to examines the ductility of square concrete column specimen with high and normal concrete's class, with or without steel fibre in normal temperature. The test results will be validated the value of the increase confined concrete stress during peak load $(K)$ to the models that had been developed by the previous experts. The results showed that the increase in strength and ductility of confined steel fibre concrete was influenced by: (1) concrete compressive strength ( $\left.f c^{\prime}\right),(2)$ whether or not steel fibers in concrete and (3) lateral rebar spacing $(s)$.
\end{abstract}

Keywords: steel fibre, compressive strength, square column 


\section{PENDAHULUAN}

Struktur bangunan di Indonesia beresiko terdampak gaya gempa yang menyebabkan kolom mengalami deformasi sehingga selimut beton terkelupas dan menyisakan inti beton yang harus mampu mempertahankan kekokohan dan daktilitasnya sebelum bangunan tersebut betul-betul runtuh. Penelitian Antonius dkk (2012) menyatakan bahwa penggunaan beton berserat kawat baja pada suhu tinggi menghasilkan daktilitas yang tinggi sehingga cocok dipakai di daerah rawan gempa. Riset ini merupakan kelanjutan dari penelitian Antonius dkk di atas untuk menguji sampai sejauh mana tingkat kekangan kolom beton yang mengandung serat kawat baja. Metoda penelitian berupa melakukan eksperimen di laboratorium dengan memberi variasi beban tekan konsentris pada benda uji baik yang mengandung tulangan lateral atau tidak. Penelitian ini diharapkan dapat memprediksi gambaran perilaku beton berserat baja terkekang yang mengalami beban konsentris.

\section{LANDASAN TEORI}

Filosofi penambahan serat baja adalah memberikan tulangan dalam bentuk potonganpotongan serat yang disebarkan secara merata pada material beton dengan tujuan untuk mengisi rongga udara yang ada sehingga mempererat adhesi pasta semen, pasir, kerikil dan air, yang pada akhirnya akan mencegah munculnya keretakan akibat beban yang bekerja. Serat baja mempunyai kekuatan serta modulus elastisitas yang cukup tinggi dan tidak berubah bentuk akibat pengaruh alkali dalam semen. Selain itu pembebanan menerus dalam jangka waktu panjang tidak banyak berpengaruh terhadap sifat mekanik baja selama tidak melampaui batas leleh. Kelemahannya adalah jika serat baja tidak terlindung dalam beton, maka dapat mnimbulkan resiko korosi (ACI, 2011). Sifat adhesi yang tinggi dari serat baja juga dapat mengakibatkan balling effect, yaitu serat tidak tersebar merata pada saat diacmpur tetapi menggumpal menjadi suatu bola-bola serat. Penambahan steel fibers dengan orientasi random akan meningkatkan kuat lentur beton fiber dibandingkan dengan beton tanpa fiber. Sifat getas beton dapat diatasi oleh fiber sehingga beton fiber menjadi liat (Soroushian dan Bayasi, 1992). Penambahan fiber pada beton akan menambah kekuatan dan mengurangi lendutan (Mansur dkk., 1997), sedangkan Balaguru dan Ramakrishnan (1986) menjelaskan bahwa peningkatan kekuatan tekan beton berserat akan diikuti mode keruntuhan yang lebih getas.

Kekangan pada beton dapat dibedakan menjadi 2 macam, yaitu kekangan yang bersifat pasif, berupa kekangan oleh tulangan lateral berbentuk spiral ataupun persegi, dan kekangan yang bersifat aktif yaitu kekangan yang ditimbulkan sifat ekspansif fluida (Soehartono, 2004). Pada kekangan pasif, tekanan lateral yang diberikan tidak konstan seperti kekangan aktif, tetapi tergantung pada deformasi aksial dari inti beton dan perilaku tegangan-regangan tulangan lateral. Kekangan pada beton juga dapat meningkatkan sisa kekuatan setelah runtuh (Mansur dkk, 1997. Penelitian Ganesha dkk. (1990) yang membandingkan kekangan pada beton mutu normal tanpa serat dan beton berserat menunjukkan bahwa penambahan serat fiber dapat meningkatkan kemampuan teganganregangan yang dimiliki penampang beton secara signifikan ketika terjadi beban puncak. Riset Hsu dan Tzu (1994) menyebutkan bahwa penambahan serat baja pada beton mutu tinggi akan meningkatkan regangan dan daktilitas beton saat beban puncak namun tidak signifikan menambah kuat tekan. Model Nataraja dkk (1999) menyatakan bahwa penambahan serat baja pada beton mutu normal dan tinggi akan meningkatkan regangan beton saat beban puncak namun tidak signifikan menambah kuat tekan. Penelitian tersebut menggunakan material setempat dengan komposisi campuran beton dan volume serat baja yang berbeda-beda.

\section{METODA PENELITIAN}

Penelitian ini dilakukan dengan metode eksperimental yaitu melakukan pengujian terhadap benda uji di laboratorium. Pembebanan terhadap benda uji beton dilakukan secara konsentris dengan tujuan untuk mempelajari perilaku struktur beton berserat mutu normal hingga mutu tinggi.. Parameter yang ditinjau meliputi kuat tekan beton $\left(f_{c}{ }^{\prime}\right)$, ada tidaknya serat baja dan spasi tulangan lateral (s). Data hasil pengujian 
divalidasi dengan model-model kekangan beton yang telah dikembangkan para peneliti sebelumnya seperti tersebut di atas. Komposisi material benda uji dapat dilihat pada tabel 1 .

Tabel 1. Komposisi campuran beton

\begin{tabular}{|c|c|c|c|c|}
\hline Material & Sumber & $\begin{array}{c}\text { Mutu } \\
\text { Normal } \\
\mathrm{f}_{\mathrm{c}}{ }^{\prime}=30 \\
\text { Mpa }\end{array}$ & $\begin{array}{c}\text { Mutu } \\
\text { Tinggi } \\
\mathrm{f}_{\mathrm{c}}^{\prime}=50 \\
\mathrm{Mpa}\end{array}$ & $\begin{array}{c}\text { Mutu } \\
\text { Sangat } \\
\text { Tinggi } \\
\mathrm{f}_{\mathrm{c}}=70 \\
\text { Mpa }\end{array}$ \\
\hline $\begin{array}{c}\text { Semen } \\
(\mathrm{Kg} / \mathrm{m} 3)\end{array}$ & $\begin{array}{l}\text { Gresik } \\
\text { Tipe 1 } \\
\end{array}$ & 350 & 419.98 & 485 \\
\hline $\begin{array}{c}\text { Abu } \\
\text { Terbang/ } \\
\text { FlyAsh } \\
(\mathrm{Kg} / \mathrm{m} 3)\end{array}$ & $\begin{array}{l}\text { PLTU } \\
\text { Tg.Jati }\end{array}$ & - & 74.11 & 82.83 \\
\hline $\operatorname{Air}(\mathrm{Lt} / \mathrm{m} 3)$ & Lokal & 200 & 160 & 140 \\
\hline $\begin{array}{c}\text { Viscocrete } \\
0,5 \%(\mathrm{lt} / \mathrm{m} 3)\end{array}$ & Sika & - & 6.23 & 9.28 \\
\hline $\begin{array}{c}\text { Agregat } \\
\text { Halus } \\
(\mathrm{Kg} / \mathrm{m} 3)\end{array}$ & Muntilan & 722.9 & 696.62 & 662.07 \\
\hline $\begin{array}{c}\text { Agregat } \\
\text { Kasar } \\
(\mathrm{Kg} / \mathrm{m} 3)\end{array}$ & Jepara & 886.8 & 1044.93 & 1080.22 \\
\hline $\begin{array}{c}\text { Kawat Baja } \\
\text { dia.0.50-1.00 } \\
\mathrm{mm} \\
\text { (\%/conc.vol) }\end{array}$ & Lokal & 0.50 & 0.50 & 0.50 \\
\hline
\end{tabular}

Pembebanan spesimen dilakukan secara konsentris, langsung dan bertahap secara monotonik. Pengujian diilaksanakan di laboratorium Uji Bahan Fakultas Teknik Undip menggunakan mesin uji tekan berkapasitas $1800 \mathrm{kN}$ dengan sistem pengujian kontrol deformasi (deformation control). Data yang diperoleh dari hasil pengujian adalah beban, deformasi kolom di daerah tes pada arah longitudinal, serta data regangan pada tulangan lateral maupun tulangan longitudinal.

\section{HASIL DAN PEMBAHASAN}

Keluaran pengujian menyajikan beberapa data yaitu : (1) kuat tekan beton normal penampang persegi $125125 \times 310 \mathrm{~mm}$ pada umur 28 hari tanpa serat (fc'), (2) tegangan puncak beton berserat dengan kekangan $\left(\mathbf{f}_{\mathrm{cc}}\right.$ '), (3) regangan puncak beton berserat tanpa dan dengan kekangan $\left(\boldsymbol{\varepsilon}_{\mathrm{co}}{ }^{\prime}\right)$, dan (4) angka peningkatan kekuatan beton berserat dengan kekangan/terkekang (K). Nilai K hasil pengujian ini selanjutnya divalidasi dengan nilai $\mathrm{K}$ dari model kekangan yang telah dikembangkan para peneliti sebelumnya yaitu Mansur (1997), Pantazopoulou dan Zanganeh (2001) serta Campione (2002), sehingga diperoleh tren nilai $\mathrm{K}$ untuk beton berserat baja penampang persegi.

Hasil pengujian menunjukkan fakta pertama bahwa dengan nilai kuat tekan beton yang semakin tinggi, dapat meningkatkan tegangan puncak dan regangan pada beton tanpa serat tanpa tulangan lateral, beton tanpa serat dengan tulangan lateral dan beton berserat dengan tulangan lateral. Selain itu diperoleh indikasi adanya proses keruntuhan beton setelah melampaui tegangan puncak yang cukup curam sehingga dapat dikatakan bahwa beton yang bermutu lebih tinggi ternyata bersifat lebih getas.

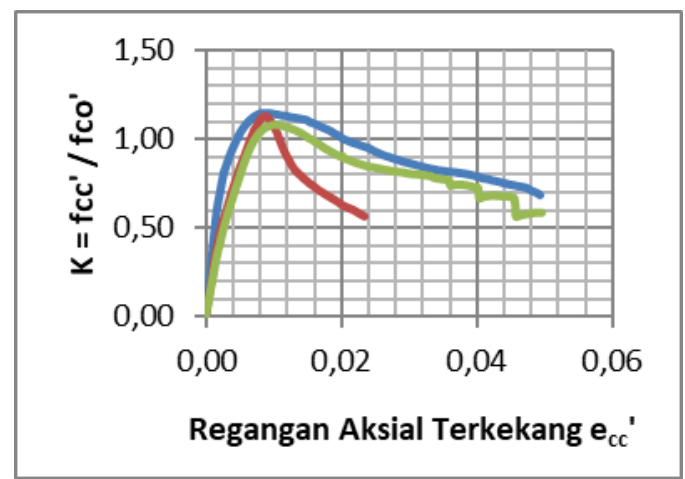

Gambar 1. Perbandingan pengaruh kuat tekan $\mathrm{f}_{\mathrm{c}}$, terhadap nilai $\mathrm{K}$

Hasil pengujian menampilkan fakta ke dua bahwa spasi tulangan lateral yang lebih rapat, dapat meningkatkan tegangan puncak dan regangan pada beton berserat yang mempunyai tulangan lateral. Selain itu terdapat kecenderungan proses keruntuhan beton setelah melampaui tegangan puncak yang lebih landai sehingga dapat dikatakan bahwa dengan spasi tulangan yang lebih rapat menyebabkan beton lebih kaku/daktail.

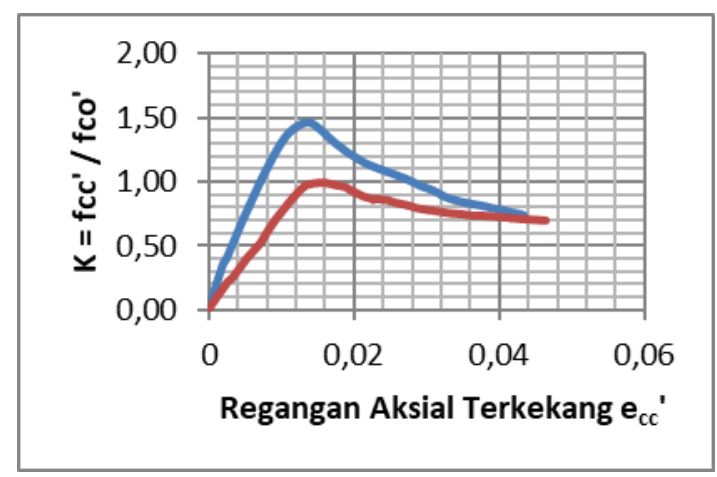

Gambar 2. Perbandingan pengaruh jarak antar tulangan lateral (s) terhadap nilai $\mathrm{K}$ 
Hasil pengujian memunculkan fakta ke tiga bahwa penambahan serat baja pada beton, dapat meningkatkan tegangan puncak dan regangan pada beton tanpa serat dengan tulangan lateral dan beton berserat dengan tulangan lateral. Selain itu didapat tren proses keruntuhan beton setelah melampaui tegangan puncak yang lebih landai sehingga dapat dikatakan bahwa dengan adanya serat baja menyebabkan beton lebih kaku/daktail.

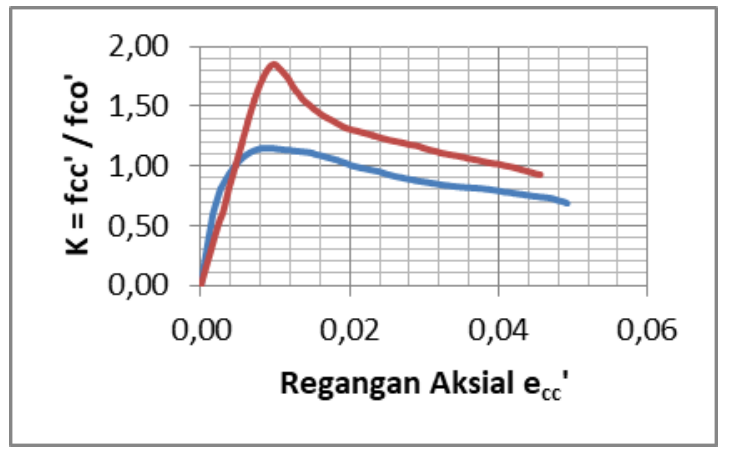

Gambar 3. Perbandingan pengaruh ada tidaknya serat baja terhadap nilai $\mathrm{K}$

Kemudian dilakukan validasi dan perbandingan nilai $\mathrm{K}$ dari hasil pengujian dengan model-model kekangan yang telah dikembangkan para peneliti sebelumnya yaitu Mansur, Pantazopoulou dan Campione. Hasil perbandingan ini dibuat dalam bentuk regresi linier sehingga dapat diketahui seberapa besar penyimpangan, tren maupun kemiripannya.

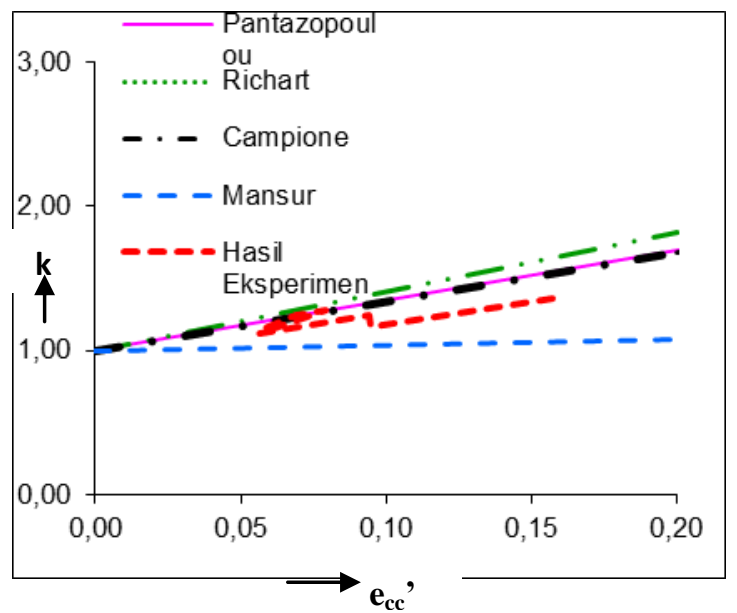

Gambar 4. Perbandingan validasi nilai $\mathrm{K}$ dengan metode regresi linier

\section{KESIMPULAN}

Hasil analisis regresi memperlihatkan adanya kemiripan antara nilai $\mathrm{K}$ hasil pengujian dengan nilai $\mathrm{K}$ dari model Campione dan Pantazopoulou sedangkan terhadap model Mansur memiliki tren yang berbeda. Oleh sebab itu pada penelitian selanjutnya tentang beton berserat baja penampang persegi, dapat dikembangkan pengembangan formulasi nilai $\mathrm{K}$ yang diturunkan dari hasil pengujian ini serta nilai $\mathrm{K}$ dari model Campione dan Pantazopoulou , untuk mendapatkan persamaan dasarnya yang sesuai dengan kondisi material dan standar konstruksi di Indonesia.

Peningkatan kekuatan dan daktilitas beton berserat terkekang sangat dipengaruhi oleh kuat tekan beton $\left(\mathrm{f}_{\mathrm{c}}{ }^{\prime}\right)$, jarak antar tulangan lateral (s) dan ada tidaknya serat baja. Penambahan fiber akan mempengaruhi besarnya tegangan beton, dengan konfigurasi yang berbeda maka akan menghasilkan kekuatan dan daktilitas yang berbeda.

\section{DAFTAR PUSTAKA}

ACI 318-11, 2011, Building Code Requirements for Reinforced Concrete and Commentary, American Concrete Institute., Detroit, Michigan.

Antonius and Imran, I., 2012, Experimental Study of Confined Low, Medium and High-Strength Concrete Subjected to Concentric Compressions, ITB Journal of Engineering Science, Vol.44, No.3, p. 252-269.

Antonius, et.al, 2012, Mechanical Properties of Gunny Sack Fiber Concrete; Proceeding of $1^{\text {st }}$ International Conference On Sustainable Civil Engineering Structures and Construction Materials (SCESCM), Yogyakarta, Indonesia, 11-13 Sept., p. 172-176.

Badan Standarisasi Nasional, 2013, SNI-2847 Persyaratan Beton Struktural untuk Gedung, BPPU, Jakarta.

Balaguru and Ramakrishnan, 1986, FreezeThaw Durability of Fibre Reinforced Concrete, Journal of The American Concrete Institute Volume 83, No. 3, May 1986, p.374-382

Campione, G. (2002), The Effects of Fibers on the Confinement Models for Concrete 
Columns, Canadian Jurnal of Civil Engineering, Volume 29, p. 742-750.

Ganesha, et.al, 1990, Strength and Behaviour of Confined Steel Fibre Reinforced Concrete Columns, ACI Structure Journal, No. 87-M.24, p. 221-227.

Hsu, L.S. and Tzu, C.T., 1994, Stress-strain Behaviour of Steel Fiber High Concrete Under Compression, ACI Structure Journal, No. 91-S.44, p. 448-457.

Mansur, et.al, 1997, Stress-strain Relationship of Confined High-Strength Plain and Fiber Concrete. Journal of Materials in Civil Engineering, Volume 9, No.4, November 1997: 171-179.

Nataraja, et,al, 1999, Stress and Strain Curves or Steel Fibre Reinforced Concrete Under Compression, Cement and Concrete Composite, No. 21, p. 383-380.

Pantazopoulou, S.J. and Zanganeh, M, 2001, Triaxial Tests of Fiber Reinforced Concrete, Journal of Materials in Civil Engineering, Volume 13, No. 5, September 2001, p. 340-348.

Soehartono, 2004, Studi Eksperimental Mengenai Efektifitas Kekangan Tulangan Lateral Pada Beton Penampang Persegi, Program Studi Pasca Sarjana Universitas Diponegoro, Semarang.

Soroushian, P. and Bayasi, Z, 1991, Fibre Type Effects on The Performance of Steel Fibre Reinforced Concrete, ACI Materials Journal, Volume 88, No. 2, Maret-April 1991.

Widayat, et.al, 2016, Pengaruh Tulangan Lateral Pada Kekangan Kolom Beton Berserat Kawat Baja Berpenampang Persegi, Program Studi Pasca Sarjana Universitas Islam Sultan Agung, Semarang. 